\title{
Prospects and Challenges in the Adoption of Energy Efficiency in the Manufacturing Industries of Ethiopia
}

\author{
Abraham Belay Berhe', Ki-Hyung Kim² \\ ${ }^{1}$ Information Network Security Agency, Addis Ababa, Ethiopia \\ ${ }^{2}$ Computer Engineering Department, Ajou University, Suwon, South Korea
}

Email address:

adigratgezana@gmail.com (Abraham B. B.), kkim86@ajou.ac.kr (Ki-Hyung K.)

To cite this article:

Abraham Belay Berhe, Ki-Hyung Kim. Prospects and Challenges in the Adoption of Energy Efficiency in the Manufacturing Industries of Ethiopia. Engineering and Applied Sciences. Vol. 2, No. 2, 2017, pp. 22-26. doi: 10.11648/j.eas.20170202.11

Received: May 17, 2016; Accepted: March 29, 2017; Published: June 23, 2017

\begin{abstract}
In the study paper presented hereunder, research study has been undertaken in closely investigating the "Prospects and Challenges in the Adoption of Energy Efficiency in the Manufacturing Sector of Ethiopia". The central problem of the study has been posed as follows: How is the adoption of energy efficiency practices in publicly owned metal manufacturing industries in Ethiopia? What are the prospects and challenges involved in realizing energy conservation practices? Answers to key and fundamental research questions pertaining to energy conservation were sought by focusing on the specific issues based on factory level assessment on the status of energy conservation in terms of technological and structural practices. Once the data is collected, this was sorted and analyzed using statistical measures based on $\mathrm{I}-\mathrm{P}-\mathrm{O}^{2}$ model framework. Based on the research findings key conclusions and recommendations have been drown.
\end{abstract}

Keywords: Energy Efficiency, Energy Conservation, Technologigal Practices, Stractural Practices

\section{Introduction}

In the last few decades, industrial energy efficiency has become an important agenda both for scholars and policy makers. One of the public concerns in relation to the use of non-renewable sources of energy is the environmental and natural resource sustainability. Despite such a concern most scholars and policy makers didn't address the importance of industrial energy efficiency in realizing the energy supply security in developing countries, knowing that the source of energy is renewable energy source.

Though Ethiopia is playing a leading role in green energy approaches by focusing only on renewable sources of energy that are environmental friendly; there are still issues that need to be addressed especially in relation to industrial energy efficiency and sustainable development. According to the three strategies forwarded above using renewable energy source alone doesn't guarantee the environmental sustainability issues as well as the energy security concerns. Therefore, the country needs to give due attention to the rest two strategies in reasonably equal magnitude along with the renewable energy generation (i.e exploitation and utilization).

The gap between energy needs and access to energy is large, and demand certainly increases as countries develop and move from agricultural led to industry led economy like Ethiopia. According to IEA (2011a), there is around a fifth of the world's population who lacks access to electricity and two-fifths rely on traditional biomass for cooking and heating. Similarly, in the case of Ethiopia, the data obtained from Ethiopian Electric Power (EEP) shows that the present energy generation capacity from hydro, wind and geothermal is $2124 \mathrm{MW}$. Electricity access is around 47 percent of the country. After the completion of the first Growth and Transformation Plan, the power generation capacity is expected to be around $10,000 \mathrm{MW}$, which is about five times the current national installed energy generation capacity (EEPCo, 2013). This is an ideal plan taking into consideration only the expected generation capacity of the power sources, without taking into consideration the possible energy losses during the process of generation, transmission, distribution and use.

Therefore in this research, the study focuses on and analyzes the importance of energy efficiency measures in manufacturing sector in realizing the energy security of the country and the contribution it has in economic sustainability and growth. Moreover, the opportunities and challenges in adopting energy efficiency measures specifically in the 
selected manufacturing industries were assessed as part of this research work. Though the focus of the research was in selected manufacturing industries the analysis result of the study is likely to be applicable to other similar manufacturing industries and the manufacturing sector at large and hence be a useful input to the policy makers as well.

\section{Statement of the Problem}

The general problem of the study was: How may the prospects and challenges of implementing energy conservation (efficiency) measures, in the context of two publicly owned metal manufacturing industries of Ethiopia, be identified?

Specifically, the study sought answers to the following questions.

A. How may the profile of the respondents be described in terms of:
a) year of experience;
b) educational qualification; and
c) Position of work?

B. What was the status of energy conservation and energy efficiency in the context of Ethiopia and within the selected manufacturing industries in terms of:
a) technological practices; and
b) Structural practices?

C. What were the prospects and challenges in adopting industrial energy efficiency measures in terms of:

a) Technological; and

b) Structural perspectives?

D. What was the role (implication) of energy efficiency in realizing:

a) Energy security; and

b) Economic growth of the nation?

E. What energy efficiency measures could be proposed to minimize the energy intensity in industries in Ethiopia? And, how can government policy induce this?

\section{Literature Review}

According to [1], energy efficiency is defined as the energy service provided per unit of energy input, while energy conservation is defined as a reduction in total energy of energy consumption. Hence, energy conservation is a broader term than energy efficiency, which includes any active efforts in decreasing energy consumption such as through behavioral change of workers, and structural changes. In other words, energy conservation might be realized with or without an increase in energy efficiency.

Though there are different ways of defining energy efficiency it is almost the same thing in different context. It is most widely used term, and is commonly defined as the ability to produce the same, or greater (more), output (work, services) using smaller energy inputs. Given that the energy entering a process equals the energy exiting, energy efficiency is most often defined as the ratio of the "useful output" for the given energy input [2]. In this research status of energy conservation within the industries under consideration was assessed based on three categories, these were technological, structural and behavioral perspectives.

Energy efficiency is one of the most effective mechanisms in addressing the strategic goals such as the energy security, economic growth and environmental sustainability of the nation $[3,6]$. Most literatures show that environmental sustainability is mainly affected by developing countries because the countries are considered to be on the verge of industrialization process. But, this researcher doesn't fully agree with this argument as discussed in the introduction part of this dissertation. Rather, the opposite viewpoint was being closely observed in the present study and in many other new and older industries in the country. The industrialized countries are however affecting developing countries for they affect the environment harshly for the mere reason that there were no advanced energy efficiency technology options to be used and with minimum level of awareness for green technology and sustainable development during their industrialization process.

This time thanks to technological advancement and globalization, the issue of green technology and environmental sustainability is becoming the concern of every nation for they share common environment. In Ethiopian case, all the source of electrical energy generation is from renewable source and still the government is committed in investing on environmental friendly sources to satisfy the increasing national and export demands. Moreover, most of developing countries are planning to invest in energy efficiency measures to protect the environment from GHG emission. This also shows that the contribution to climate change was and is still much higher by the industrialized countries than the countries that are not yet industrialized.

Efficient use of generated energy in manufacturing industries was the point need to be addressed in this research. There are different options to use energy consumption efficiently. Among these [4] forwarded in his book of energy efficiency in industry as; avoiding unnecessary consumption, improving efficiency, reducing specific useful energy demand, recovering energy and using renewable source of energy. Though using renewable energy source was not a concern in the case of Ethiopia manufacturing industries in general and the selected manufacturing firms in particular, but the other four options forwarded by [2] need to be incorporated as a means for energy saving mechanisms while using energy efficiently within the industries under consideration.

In earliest times, industrialization and environmental sustainability are considered to be at odds to each other. But, in recent days the industrialization process has advantages of new technological advancements and improved awareness levels to use energy efficiently and be environmental friendly [6]. This doesn't mean that developing countries don't have the contribution to the climate change rather more weight should be given to the industrialized countries especially during their industrialization process and this time as main 
consumers of non-renewable sources of energy and contributions of toxic emission to the environment.

[7] discusses about the history of energy use and energy efficiency as, increased energy use and increased energy efficiency have been one of the primary inputs/drivers of output and economic growth for the entire modernization history of over the last 200 years. But the increased focus on energy efficiency has only a history of three decades. This in effect shows that the issue of energy efficiency is timely to assess and analyze in different contexts.

There are a lot of issues not yet resolved in relation to the energy use and energy efficiency. Researchers need to go beyond demonstrations and tests of energy efficiency for applying at macro, and micro levels. In line with this argument and the fact that there are a lot of studies in energy efficiency measures, [8] expresses that; many of the suggested improvements identified in energy efficiency audits are never implemented. In Ethiopia there are concerns about energy efficiency, scholars and policy makers have reported energy efficiency and economics at macro level while any other scholar did not yet address micro level analysis. The energy efficiency in industries has great importance in the case of developing countries like Ethiopia in improving the energy coverage as well as minimizing the investment cost for renewable energy generation.

The importance of having energy efficiency measures for the firm as well as the nation needs to be communicated with every level of the management and employees. If there is no enough energy consumption and efficiency awareness within the industry employees there is no compelling reason for economical use of energy within the industry. Even there should be some mechanism to display about the energy consumption bills and define energy efficiency policies to minimize loss. Otherwise energy might be considered as free commodity as most of the workers in an organization do.

The conceptual framework of the study was discussed as shown in the figure 1 below. The framework implies the variables used in the study. There are input, process, output, and outcome (I-P-O ${ }^{2}$ ) steps in the conceptual framework in the study under consideration.

The data collected using questioners and energy-auditing processes within the factories were taken as an input to the energy conservation analysis and evaluation process. The outputs of the process were the status of energy usage, identified prospects and challenges in the adoption of energy efficiency within the factories and the proposed energy conservation measures to the factories and policy makers.

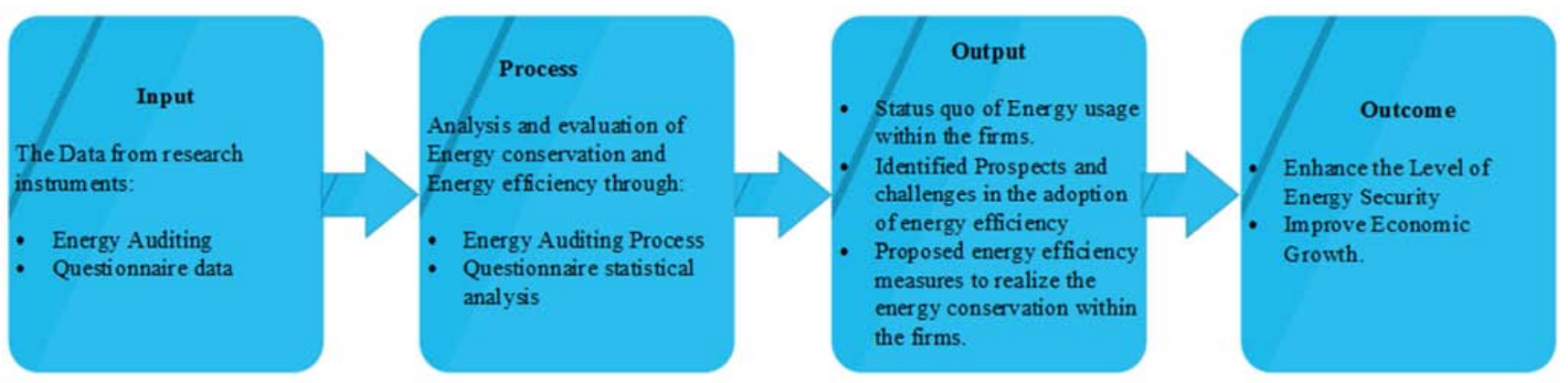

Figure 1. Conceptual Model of the Study.

The output of the process was taken as an input to the national economic growth and energy security processes which was considered as an outcome of the inputs. Hence this was the conceptual framework that the researcher used to realize the assumptions, get answers to the questions and describe their economic and social implications that the researcher raised regarding the industrial energy conservation status in Ethiopia.

\section{Summary of Findings}

The key findings of the research summarized as status of energy conservation and energy efficiency within the sample manufacturing industries; challenges in the adoption of energy efficiency measures within the sample factories; proposed government energy efficiency policy that needs to be introduced to reduce inefficient energy utilization in manufacturing industries; and social and economic implications.

\subsection{Status of Energy Conservation}

As regards to the status of energy conservation and energy efficiency within the sample manufacturing industries, though the identified opportunities are to some extent interdependent and might manifest themselves in different ways, these are categorized and presented as behavioral, technological and structural as follows:

1) Technological Practices: There are energy efficiency improvement opportunities due to improvement in power factor of the factories. There is energy efficiency improvement opportunity by improving the loading of motors to their nominal loads. There is energy efficiency improvement opportunity by leveling of the load factor. There is energy saving opportunity by proper loading of the active transformers and removing out the idle transformers.

Moreover, there is energy efficiency improvement opportunity by implementing variable speed control and automated central load management solutions. There is an additional energy saving opportunities by replacing the fluorescent lamps by energy efficient lamps. There is also energy efficiency opportunity by replacing the available old machines by newer and efficient machines. 
2) Structural Practices: The commitment of the Ethiopian Government in investing on green and sustainable development is very high. Energy conservation practices are one of the strategies used to realize sustainable development. Though they don't have enough power yet to enforce energy efficiency measures, standard and labeling, and energy auditing practices within industries there are organizations like Ethiopian Electric Agency and Quality Control Agency expected to do so if they are supported by policy, strategies and implementation programs.

\subsection{Identified Challenges}

The challenges in the adoption of energy efficiency measures within the sample factories can also be classified technologically, structurally and behaviorally as follows:

1) The identified Technological Challenges in realizing energy efficiency: Almost all the machines are not new and their performances are poor. Hence they need improvements in their performance and energy use. The investment cost to implement energy efficiency technologies is not small. Lack of technical support and experience sharing from local expertise and industries in energy efficiency technologies and practices is there. Limited access to relevant energy efficiency technologies available in the world market is observed. A rapid change in energy efficiency technologies that hinders from investing in the currently available energy efficiency technologies is there. Interfacing and upgrading problems of the old machines to control centrally monitor and control the machines.

2) The Structural Challenges identified to realize energy efficiency: Lack of energy efficiency policy at national level that gives enough power to responsible authority and private investors and enforce energy users to implement energy efficiency measures. Since the factories work based on the order come from customers it is difficult to implement load management practice to improve the load factor variation. There is no financial incentive and motivational factors to energy users as well as private organizations to invest in energy efficiency technologies.

Moreover, there is lack of skilled private sectors and government organizations that can give support and create awareness to industries in energy management practices and in implementing energy efficiency measures. Lack of standard operational and maintenance procedures within the factories; lack delegated person or group of persons within the industries to manage the energy use within the factories. Lack of labeling and standard for energy use appliances that might have large energy saving potential if realized and there is no responsible organization to manage this at national level. Price oriented purchasing of equipment and machineries that result in higher overall cost to maintain and repair them and higher energy use of the machines.

\subsection{Energy Policy Consideration}

Government energy efficiency policy needs to be introduced to reduce energy intensity in manufacturing industries. The energy efficiency and conservation opportunities and challenges identified within the manufacturing industries are multi-faceted and diverse. This also implies that effective energy efficiency policy solution is called for to address the identified challenges and exploit the opportunities.

\subsection{Social and Economic Implications}

In relation to the social and economic implications it is important to note that, first; only through by replacing the inefficient lamps with CFL and deploying central power factor corrector capacitor bank around 11,514 households in remote areas can get electricity as their light source. Second, as many scholars from the economics discipline as well as the basic thermodynamics laws show, there is positive relationship between energy efficiency measures and productivity of the industries and then overall economic growth of the nation in Ethiopian context as well.

\section{Conclusions}

The following conclusions are drawn based on the findings:

There is considerable energy conservation potential identified within the growing industries investigated particular, and possibly throughout Ethiopia. These potentials involve improving the overall power factor of the factories from 0.6 to 0.95 by implementing power factor corrector, replacing the inefficient fluorescent lamps by efficient compact fluorescent lamps, proper loading of the machines to improve the energy use by the machines, using more efficient machines.

There are identified as energy conservation practices that need to be implemented within the factories in terms of technological, structural and behavioral practices. These practices involve, first behavioral such as renaissance thinking by creating awareness to all stakeholders through training and development, create expertise in energy conservation practices, and implement incentive mechanisms to motivate factory owners as well as private sector to invest in energy efficiency measures.

Second technological such as implementing automated control system for all or selected machines within the industries, improve the power factor of the industries by implementing power factor corrector, implement load management and proper loading of motors, using efficient light sources. Third structural such as crafting effective energy efficiency policy, develop standard operational and maintenance procedures.

Implementing energy efficiency measures within industries will improve the energy security as well as economic growth of the country. Any other energy customers could use the energy conserved from the industries and enhance the energy security within the country. The energy conservation practices also improve the productivity of the firm, create new jobs and realize sustainable development of the nation.

Based on the research findings and within the national 
policy and frameworks, such prospects seem to be decisive and in line with the attainment of the Millennium Development Goals and the achievement of the rapid growth of the industrial sector in the country as stipulated in Ethiopia's Growth and Transformation Plan (GTP). Hence, renaissance thinking and approach in Ethiopian industrial management is needed.

\section{Recommendations}

\section{A. Study Recommendations}

On the basis of the findings and conclusions of the study, the following were the recommendations to minimize the energy wastage correspondingly within the sample factories as well as the manufacturing sector at large:

1. There are pressing needs to improve the overall power factor of the factory by implementing compensation capacitor,

2. There are needs to improve the energy efficiency awareness level of the personnel involved through training and education,

3. Developing standard maintenance and operational procedures at factory level and implementing labeling and standard of electric appliances at national level is also important in minimizing energy usages.

4. Emphasis has to be made on the importance of implementing energy auditing practices to identify the possible energy efficiency improvement potentials within the firms,

5. Crafting suitable energy efficiency policy is mandatory to enforce and motivate energy efficiency measures.

B. Recommendations for Future Research Work

Key energy conservation opportunities have been identified based on the findings of the research and the results discussed above. However, there are things that cannot be covered for time and other limitations. Therefore, the following potential areas have been suggested where future research works relating to industrial energy efficiency should be focused.

1. One element of work addressed in this study that requires further research is to adopt practical and appropriate approach that will include more industries, and all kinds of energies.

2. Another direction for future research will be to consider the areas that have not been addressed in this research is analyzing the environmental impacts of industrial energy efficiency measures.

3. Additionally, another area for further research will be the economic and energy security implications of industrial energy efficiency measures required to be more specified and parameterized using econometric analysis models.

\section{Acknowledgment}

First and foremost, I would like to extend deepest gratitude to my wife Halal Hailu, with our lovely kids Dinah, Efron Nathan and Ethan, for her endless love, inspirations, understanding, and encouragement, moral and emotional support she has showered me all the past years of my study.

Above all, I would like to acknowledge and express my sincere appreciations to all senior academicians, and institutions for extending their contributions and support to my research work.

At last but not least, I thank God who makes this to happen!

\section{References}

[1] Frank Kreith and D. Yogi, 2007. Handbook of Energy Efficiency and renewable Energy.

[2] International Energy Agency. Renewable Energy: Policy Considerations for Deploying Renewable (IEA, France, 2011, a).

[3] International Energy Agency. World Energy Outlook 2010: Executive summary (Paris, IEA, 2010).

[4] Jamie Howland and Derek Murrow. Energy Efficiency: Engine of Economic growth, a macroeconomic modeling assessment (2009).

[5] Kenneth Gillingham, Richard G. Newell, and Karen Palmer. Energy Efficiency Economics and Policy (Annual Review of Resource Economics, V. 1, pp. 597-619, 2009).

[6] McCabe, Jin. From audit to action: explains how to deliver real energy savings (Journal of energy efficiency', Journal of Energy Efficiency, September 2008, pp.37-39 2008).

[7] Price, L. and McKane, A., Industrial Energy Efficiency and climate change mitigation (Policies and Measures to Realize the Potential in the industrial Sector, 2009).

[8] Rath, A., 2011. Industrial Energy Efficiency, Economic Development and Poverty Reduction. WP 07/2011. Vienna: United Nations Industrial Development Organization.

[9] Sirchis J.: Energy efficiency in industry, 2005.

[10] Steve Sorrell, Alexandra Mallett, and Sheridan Nye. Barriers to industrial energy efficiency: A literature review, United Nations Industrial Development Organization (UNIDO, Vienna, 10/ 2011). 